\title{
Community and Health Facility Influences On Contraceptive Method Choice in the Eastern Cape, South Africa
}

\section{By Rob \\ Stephenson, \\ Andy Beke and \\ Delphin Tshibangu}

Rob Stephenson is assistant professor, Hubert Department of Global Health, Rollins School of Public Health, Emory University, Atlanta, GA, USA. Andy Beke is lecturer and director of the regional training program, School of

Health Systems and Public Health, University of Pretoria, Pretoria, South Africa. Delphin Tshibangu is with the City of Tshwane Metropolitan Council, and is lecturer at the School of

Health Systems and Public Health, University of Pretoria. CONTEXT: Although a growing number of studies have examined how community factors influence contraceptive
use, few have explored how such factors affect method choice.

METHODS: Data from the 1998 South Africa Demographic and Health Survey and the 1998 Eastern Cape Facility Survey were used to examine community and health facility influences on the method choices of 1,165 women aged 15-49 who lived in the Eastern Cape. Relative risk ratios from multilevel multinomial models assessed how method choice varied between communities.

RESULTS: The likelihood of using the pill or a more permanent method rather than the injection rose with the proportion of women in a community who controlled their earnings (risk ratios, 3.2 and 3.8, respectively). In communities with higher proportions of females with only a primary education, women were less likely to use the pill instead of the injection (0.1). Higher doctor staffing levels were associated with a greater likelihood of using the pill or a more permanent method (1.5 and 1.4), and having more expired methods in stock was associated with increased use of a more permanent method (2.1). Several facility factors were associated with a decreased likelihood of using the pill rather than the injection: higher numbers of community health workers in an area and higher numbers of facility nurses who had received training on HIV/AIDS in the last year (0.9 for each). Yet a substantial amount of variation in method choice was not accounted for by these variables.

CONCLUSION: Future research should emphasize the collection of community-level data on structural, behavioral and cultural factors to help explain the variation in method choice between communities.

International Family Planning Perspectives, 2008, 34(2):62-70

South Africa's demographic transition is considerably more advanced than those of other Sub-Saharan African nations; its total fertility rate (TFR) has declined from approximately 6.0 births per woman in 1980 to 2.2 in 2007. ${ }^{1,2}$ Over the same period, contraceptive use among the four major population groups (black, white, colored and Asian) has increased. ${ }^{3,4}$ Yet the overall modern contraceptive prevalence of $61 \%$ (urban 66\%, rural 53\%) masks wide racial disparities, and injectables represent $30 \%$ of all use. ${ }^{1,4}$ These contraceptive patterns exist in the context of high levels of HIV, which in 2007 infected 19\% of all adults. ${ }^{5}$ Previous studies of the determinants of contraceptive use in South Africa have focused on individual and household-level influences. ${ }^{3,5,6}$ In general, little research has examined the role of community context in shaping contraceptive method choice, although a few studies have examined how communities shape contraceptive adoption. ${ }^{7-9}$

Contraceptive method choice is a fundamental indicator of quality of care in a family planning program: The more contraceptive methods that are available, the more likely it is that a program can meet the range of contraceptive needs of a diverse client population. ${ }^{10}$ Method choice is particularly important in settings with a high prevalence of HIV, such as South Africa. For women who wish to avoid pregnancy, the dual method approachcombining condoms for HIV and STI prevention with longer acting, more effective contraceptives for added protection against pregnancy-prevents both heterosexual and perinatal HIV transmission. ${ }^{11}$ Some studies have shown that seropositive women are more likely than seronegative women to adopt permanent or barrier methods of contraception as a way to prevent pregnancy or HIV transmission, respectively, ${ }^{11,12}$ whereas others have shown that pre-seroconversion fertility desires often reemerge in an environment of low contraceptive use and cultural constructs that support high fertility. ${ }^{13,14}$

This study uses data from the Eastern Cape Province, an area with poor economic and health indicators, to examine how community and health care infrastructure characteristics may influence a woman's method choice, particularly the use of contraceptives other than injectables, which are currently the most popular method in South Africa. In an environment of high levels of heterosexually transmitted HIV, the availability of a variety of methods is critical in allowing women to both manage their fertility desires and protect against HIV transmission. Understanding how the community environment shapes contraceptive method choice in this context has the potential to enhance both family planning and HIV prevention efforts. 


\section{BACKGROUND}

The last decade has seen a growth in the application of social epidemiology, an approach that emphasizes social conditions as fundamental influences on people's health; it arose from an interest in understanding how individual health outcomes and behaviors are influenced by factors beyond the household. ${ }^{15-24}$ In a social epidemiology approach, the influence of social factors on health outcomes is the focus of analysis; that is, the factors are not simply adjusted for or used as proxies for individual risk factors. ${ }^{15-17}$ This approach has been made easier by the development of multilevel modeling techniques, which provide a robust method for analyzing hierarchically clustered data while allowing the measurement of the influence of observed and unobserved community factors on health outcomes. ${ }^{23,25-27}$ However, many studies of community influences on health have focused on one aspect of the community environment, or on characteristics of the health care infrastructure in isolation, with few studies attempting to simultaneously quantify community social, economic, cultural and health care influences on health behaviors.

The number of studies examining how community contextual factors influence contraceptive use has recently grown, $,{ }^{9} 20,28,29$ yet attention to how such factors influence contraceptive method choice has been limited. At the community level, studies of contraceptive use have focused on the influence of health service characteristics, primarily the influence of quality of care on contraceptive adoption. ${ }^{30-33}$ Clear associations have been found between quality of care indicators, such as distance to service and provider attitudes, and contraceptive adoption. ${ }^{34-39}$ In a comparison of 15 countries, Blanc et al. showed that within a year of starting a method, $7-27 \%$ of women ceased to practice contraception for reasons related to the quality of the service environment. ${ }^{40}$ The provision of a range of contraceptive methods at family planning services has also been shown to influence contraceptive adoption. ${ }^{34-39}$ However, there is less evidence for how community factors unrelated to health facilities influence contraceptive use.

In a U.S. study, Grady et al. found that rapid population growth, high rates of unemployment, elevated levels of religious affiliation, higher socioeconomic status and ready access to family planning services were all associated with increased uptake of contraceptives. ${ }^{18}$ Similarly, DeGraff et al. found that the presence of family planning services and community labor-market conditions and infrastructure development were strong influences on contraceptive use in the Philippines. ${ }^{41}$ Some studies have examined other community characteristics, including the influence of levels of community economic development, ${ }^{9,42-45}$ levels of school participation, ${ }^{19,41}$ economic roles of children ${ }^{46,47}$ and community fertility norms ${ }^{31,43,48}$ on contraceptive use.

To date, little research has examined how community factors shape contraceptive method choice. Previous work has demonstrated that measures of availability (e.g., distance to services or number of methods available at a clinic) do not completely explain the contraceptive choices made by women. In a study of contraceptive choice in rural Thailand, Entwisle et al. showed the importance of social networks in shaping individual method choice, suggesting that method dominance within villages reflects a process in which women acquire knowledge from other contraceptive users in the village, perpetuating the use of certain methods within communities. ${ }^{29}$ Thus, community and health facility characteristics may influence women's contraceptive choices through the availability of services and the manner in which they are presented, as well as through the prevailing attitudes toward contraception. However, research on how community and health facility characteristics influence contraceptive method choice is missing from the literature. This study explores a range of such influences on contraceptive method choice in Eastern Cape, South Africa, and focuses on methods other than injectables, the most commonly used method. A better understanding of how community-level characteristics affect method choice will help inform the development of community-based family planning programs that aim to expand contraceptive method choices.

\section{Study Setting}

Eastern Cape is the third most populous province in South Africa, and is also the second poorest; at nearly $50 \%$, its unemployment rate is the country's highest. ${ }^{49}$ Prior to 1994 , Eastern Cape comprised three regions (Cape Provincial Authority and two independent black homelands, Ciskei and Transkei); by 2000, the province was under one authority and health care was managed by seven district councils. ${ }^{49}$ Eastern Cape has some of the worst health indicators in South Africa, with higher-than-average levels of child mortality and lower-than-average levels of childhood immunization. Its TFR of 3.5 births per woman in 1998 (the most recent data available) was well above the national average of 2.9, and it had a relatively low modern contraceptive prevalence of 59\%. ${ }^{1}$ In Eastern Cape, as in most of South Africa, injectables were the predominant method, used by $37 \%$ of women aged $15-49 .{ }^{1}$ The proportion of women reporting met demand for family planning was in line with that of most of the other provinces (68\%, compared with 45-71\%), although it had the lowest percentage of women reporting exposure to family planning messages in print media (31\% vs. $35-44 \%$ ). ${ }^{1}$ However, family planning services were almost universally available at government clinics in Eastern Cape, and some quality of care indicators, such as method availability and uninterrupted electricity supply, were higher than the national average. ${ }^{50,51}$ On the other hand, Eastern Cape government clinics had the lowest proportion of doctor-staffed health facilities in any province except Northern Province.

\section{DATA AND METHODS}

Individual, household and community data came from the 1998 South Africa Demographic and Health Survey (DHS), which used a stratified, multistage cluster design to collect information from a nationally representative sample of all 
women aged 15-49. Eligible women in sampled households completed questionnaires about their fertility, contraceptive use, and demographic and socioeconomic characteristics. The 1998 Eastern Cape Facility Survey (ECFS) collected information from 624 government clinics, which were selected on the basis of proximity to the primary sampling units surveyed in the DHS. Nurses were interviewed about staffing and recent staff training, supervision visits, availability of drugs, supplies and basic infrastructure, emergency services, transportation availability and referral systems. Information was also collected on the number of family planning methods offered, whether each of the methods was in stock, whether stock had expired and the family planning training received by staff.

ECFS data were linked to the DHS data using the global positioning system coordinates for the facilities and households, so that each household was linked to the nearest government clinic. Because geographic coordinates were not available for all households, the center of each of the 209 DHS enumeration areas was used as the approximate location for that area's households, and the distance was calculated to the nearest clinic included in the ECFS for which we had coordinates. Each enumeration area was linked in this manner to the five closest clinics. ${ }^{51}$ (This approach may have omitted linkages between clinics and households that were close to the periphery of the enumeration districts.) Overall, 174 of the 624 surveyed clinics were linked to primary sampling units; the remaining clinics were located in areas that were not as close to the sampled populations. For each individual, the facility indicators thus represent the average across the five closest clinics in the enumeration area in which the individual resided.

The DHS sampled 2,756 women aged 15-49 who were from the Eastern Cape. After exclusion of women who reported that they had never had sexual intercourse (361), were pregnant (100), were infecund (33) or were not currently using a contraceptive method (1,097), our final sample included 1,165 women. We excluded women who were not using contraceptives to avoid modeling the differential decision processes of choosing to adopt contraception and choosing a specific contraceptive method. To examine this, we conducted an analysis in which women who were not using a contraceptive were the reference category, such that the determinants of the choice of each method type were modeled against contraceptive nonuse. The results found little variation in the factors associated with each of the contraceptive methods, indicating that the model was largely driven by the decision to adopt any form of contraception

\footnotetext{
*The model is written as

$\log \left(\prod_{i j}^{(s)} / \prod_{i j(t)}\right)=\beta_{0}^{(s)}+\beta_{1}^{(s)} \chi_{i j}+v_{j}^{(s)}, s=1, \ldots, t-1$.

If $\gamma_{i j}$ is the categorical response for woman $i$ in district $j$, then the probability of being in category $s$ is denoted by $\prod_{i j}^{(s)}$, where $v_{j}^{(s)}$ is a communitylevel random effect assumed to be normally distributed with mean 0 and variance $\sigma_{u}^{2(s)}$. The random effects are contrast-specific, as indicated by the $S$ superscript, because different unobserved community factors may affect each contrast. Thus, the intracommunity correlation in contraceptive use may vary by type of method.
}

(not shown). Because the inclusion of nonusers obscured the variation in the factors associated with the use of each method, this group was omitted from the final analysis. Thus, the dependent variable is a categorical variable in which women are classified as using a method belonging to one of three groups: injectables (reference group), the pill, or the IUD or female or male sterilization.

\section{Analysis}

The DHS data set has a hierarchical structure, with women nested within households and households within primary sampling units, thus violating the assumption of independence required for ordinary logistic regression models. A multilevel modeling technique was employed to account for this hierarchical structure, to facilitate the estimation of community-level influences on contraceptive method choice and to correct the estimated standard errors to allow for clustering of observations within units. ${ }^{26}$ Multilevel models allow the identification of clustering in method choice (also known as the random effect), providing a measure of the extent to which the likelihood of reporting the use of each contraceptive category varies among communities, while also controlling for a range of individual, household, health facility and community factors thought to influence the outcome. A multinomial multi-level model was fitted to the categorical outcome of method choice, using the MLwiN software package. ${ }^{* 52}$

The variables entered into the model were grouped into individual, household, community and health facility categories. All variables were included, although only results for those that proved to be associated with contraceptive method choice are presented. We conducted tests for correlations between independent variables, and included variables for which the correlation coefficient was below .05. Interactions between variables were also tested, although no significant ones were found.

The choice of individual and household independent variables was informed by previous studies on the factors influencing contraceptive method choice. Because the topic of how community environments influence method choice is a relatively new area of investigation, there is presently a lack of theory to provide a framework for selecting community-level variables to be included in such analyses. Our choice of community and health facility factors was informed by a review of the literature on the dimensions of community environments and quality of care that have been shown to influence other reproductive health behaviors.

Community-level factors were derived from individual data by aggregating individual responses to the primary sampling unit and subtracting the index response. In the absence of quality community-level data, derived variables have proven to be an effective mechanism for capturing community-level influences on individual-level outcomes. ${ }^{53}$ Sampling units with fewer than 10 respondents (three) were omitted; the range of respondents in the remaining units was $12-27$, with a mean of 15 . For commu- 
nity factors, the analysis considered the proportions of women who control their earnings and who have only a primary education, women's mean age at first sexual intercourse (15 or younger, 16-20, 21 or older), mean spousal age difference and mean household asset score. ${ }^{*}$ We examined several health facility and service factors: number of doctors at facilities, number of community health workers in primary sampling units, number of facility nurses trained in HIV/AIDS in the last year, number of expired contraceptive methods in stock and facility asset score. ${ }^{\dagger}$

\section{RESULTS}

Sixty-nine percent of women were using the injection, 17\% the IUD or male or female sterilization, and $15 \%$ the pill (Table 1). A large majority of the sample was black, half had at least three children and nearly three-fourths were unemployed. The mean household asset score was 4.2 (range, 0-11), as was the mean household community score. At the community level, the proportions of women who controlled their own earnings and who had only a primary education were $33 \%$ and 30\%, respectively. The mean age at first sexual intercourse was 16.1 years, and the mean spousal age difference was 2.3 years. Regarding health facility measures, the mean number of doctors at facilities was low (0.3), whereas the mean number of community health workers in the primary sampling units was 30.1. The average number of facility nurses who had been trained in HIV/AIDS in the last year was 1.3, and the average number of expired methods in stock was 0.3. Finally, the mean facility asset score was moderately high at 7.3 (range, 2-10).

The only individual-level factor that was consistently associated with the contraceptive method choices was race or ethnicity. Compared with black women, colored and white women were more likely to report using the pill (risk ratios, 2.2 and 6.0, respectively) or relying on a more permanent method of contraception (IUD or male or female sterilization; 2.6 and 6.0) than using the injection (Table 2 , page 66). Women residing in urban areas were less likely than those in rural areas to be using the pill instead of the injection (0.5), but were more likely to be using a more permanent contraceptive method in lieu of the injection (1.4). Women who worked outside the home were more likely than those who were not employed to be using the pill instead of the injection (2.5).

Relative to women aged 40-49, those aged 15-34 were less likely to be using a more permanent method instead of the injection (risk ratios, 0.04-0.2). Regarding parity, women with five or more children were more likely than women with none to be using a more permanent method

*The household asset score is a summative index of 11 amenities and goods: piped water, electricity, flush toilet, radio, television, refrigerator, bicycle, motorcycle, car, and floor (vinyl, carpet, tile, concrete, wood) and wall material (cement, corrugated iron/zinc, brick).

†The facility asset score is a summative index of 10 elements: condoms available in reception, displayed map of catchment area, adult and infant scales, telephone, fax machine, two-way radio, refrigerator, stethoscope and sphygmomanometer. of contraception rather than the injection (3.2). Finally, women living in wealthier households were less likely than those in poorer households to be using a more permanent method in lieu of the injection (0.9).

At the community level, the likelihood that women were using either the pill or more permanent methods of con-

TABLE 1. Percentage distribution of 1,165 sexually experienced women aged 15-49 who were using a contraceptive method, by selected characteristics; and means (and ranges) of household, community and health facility measures, Eastern Cape, South Africa, 1998 Demographic and Health Survey and 1998 Eastern Cape Facility Survey

Characteristic

$\%$ or mean

INDIVIDUAL

Contraceptive method

Injectable

Pill

IUD, male/female sterilization

Age

15-19

20-24

25-29

30-34

35-39

40-49

Residence

Rural

Urban

Race/ethnicity

Black

Colored

White

Parity

0

$1-2$

3-4

24.4

23.2

$\geq 5$

20.5

Employment status

Not working

Employed outside the home

73.4

26.6

Total

100.0

HOUSEHOLD

Mean asset score†

$4.2(0-11)$

COMMUNITY

$\%$ of women who control their earnings

$33.2(0-100)$

$\%$ of women with only a primary education

$29.6(0-100)$

Mean age at women's first sexual intercourse $\quad 16.1(11.6-22.3)$

Mean spousal age difference

$2.3(0-12.1)$

Mean household asset score

$4.2(0-11)$

HEALTHFACILITY

Mean no. of doctors at facilities $0.3(0-4)$

Mean no. of community health workers in PSU $30.1(0-301)$

Mean no. of facility nurses trained in HIV/AIDS

in last year

Mean no. of expired methods in stock

$30.1(0-301)$

$1.3(0-16)$

$0.3(0-2)$

$7.3(2-10)$

†The household asset score is a summative index of 11 amenities and goods: piped water, electricity, flush toilet, radio, television, refrigerator, bicycle, motorcycle, car, and floor (vinyl, carpet, tile, concrete, wood) and wall material (cement, corrugated iron/zinc, brick). ¥The facility asset score is a summative index of 10 elements: condoms available in reception, displayed map of catchment area, adult and infant scales, telephone, fax machine, two-way radio, refrigerator, stethoscope and sphygmomanometer. Notes: Health facility measures are based on data from 174 clinics.PSU=primary sampling unit. 
TABLE 2. Relative risk ratios (and 95\% confidence intervals) from multilevel multinomial models examining the likelihood of choosing selected contraceptive methods instead of the injection

Characteristic

Pill vs. injection

IUD or male/ female sterilization vs.injection

INDIVIDUAL

Age

15-19

20-24

25-29

30-34

35-39

40-49 (ref)

Residence

Rural (ref)

Urban

Race/ethnicity

Black (ref)

Colored

White

Parity

0 (ref)

$1-2$

3-4

$\geq 5$

\section{Employment status}

Not working (ref)

Employed outside the home

$2.53(1.65-3.87)^{*} \quad 1.22(0.80-1.87)$

HOUSEHOLD

Asset score $†$

$0.94(0.86-1.03)$

$0.90(0.80-0.99)^{*}$

COMMUNITY

$\%$ of women in PSU who control their earnings

$\%$ of women in PSU with only a primary education

Mean age at women's first sexual intercourse in PSU

Mean spousal age difference in PSU

Mean household asset score in PSU

HEALTH FACILITY

No. of doctors at facilities

No. of community health workers in PSU

No. of facility nurses trained in HIV/AIDS

in last year

No. of expired methods in stock

Facility asset score‡

Community-level random intercept

$0.72(0.35-1.46) \quad 0.04(0.01-0.06)^{*}$

$0.69(0.35-1.38) \quad 0.04(0.01-0.06)^{*}$

$0.79(0.39-1.60) \quad 0.05(0.01-0.07)^{*}$

$0.96(0.47-1.97) \quad 0.18(0.10-0.32)^{*}$

$0.98(0.46-2.07) \quad 0.70(0.42-1.14)$

1.00

1.00

$\begin{array}{ll}1.00 & 1.00 \\ 0.51(0.32-0.81)^{*} & 1.41(1.04-2.83)^{*}\end{array}$

$\begin{array}{ll}1.00 & 1.00 \\ 2.18(1.20-3.97)^{*} & 2.64(1.43-4.89)^{*} \\ 5.98(1.62-9.52)^{*} & 5.96(3.03-8.14)^{*}\end{array}$

$1.00 \quad 1.00$

$0.54(0.33-0.89) \quad 0.87(0.26-2.92)$

$0.56(0.31-1.01) \quad 1.92(0.63-5.84)$

$0.53(0.25-1.13) \quad 3.19(1.05-6.12)^{*}$

$3.16(1.84-5.14)^{*}$

$0.14(0.05-0.38)^{*}$

$2.78(1.68-4.61)^{*}$

$0.91(0.38-2.20)$

$1.26(1.12-1.41)^{*} \quad 1.09(0.98-1.20)$

$1.04(0.95-1.15) \quad 1.18(1.08-1.29)^{*}$

$1.06(1.03-1.11)^{*} \quad 1.11(1.02-1.21)^{*}$

$1.48(1.19-1.85)^{*} \quad 1.38(1.12-1.69)^{*}$

$0.89(0.79-0.99)^{*} \quad 0.99(0.98-1.02)$

$0.91(0.83-0.99)^{*} \quad 0.97(0.90-1.04)$

$0.78(0.28-2.12) \quad 2.08(1.03-4.46)^{*}$

$1.11(0.99-1.24) \quad 1.15(1.03-1.29)^{*}$

$2.04(0.20)^{*}$

$3.43(0.32)^{*}$
${ }^{*} \mathrm{p}<$ <05. TThe household asset score is a summative index of 11 amenities and goods: piped water, electricity, flush toilet, radio, television, refrigerator, bicycle, motorcycle, car, and floor (vinyl,carpet, tile, concrete, wood) and wall material (cement, corrugated iron/zinc, brick). $¥$ The facility asset score is a summative index of 10 elements: condoms available in reception, displayed map of catchment area, adult and infant scales, telephone, fax machine, two-way radio, refrigerator, stethoscope and sphygmomanometer. Notes: Household, community and health facility measures were analyzed as continuous variables, and the risk ratios reflect increased or decreased risk relative to each measure. For each individual, the facility indicators were averaged across the five closest clinics in their enumeration area. PSU=primary sampling unit.

traception rather than the injection rose with the proportion of women in the neighborhood who controlled their own earnings (risk ratios, 3.2 and 2.8, respectively), while the likelihood of using the pill in lieu of the injection declined as the proportion of women in a community who had only a primary education increased (0.1). The higher the mean age at first sexual intercourse among women in the community, the higher the likelihood of using the pill instead of the injection (1.3). Women who lived in communities in which there was a higher mean spousal age difference were more likely than those in communities with a lower spousal age difference to be using a more permanent method rather than the injection (1.2). Residence in a community with a higher mean household asset score was associated with an increased likelihood of using either the pill or a more permanent method instead of the injection (1.1 for each).

At the health facility level, the likelihood of using the pill or a more permanent method rather than the injection rose with the number of doctors at health facilities in the community (risk ratios, 1.5 and 1.4 , respectively), and use of the pill in lieu of the injection was negatively associated with the number of community health workers in an area and the number of health facility nurses who had received training on HIV/AIDS in the last year (0.9 for each). Furthermore, the likelihood of using a more permanent method instead of the injection rose with the number of expired contraceptive methods in stock at the community health facility (2.1). Finally, the higher the asset index score at the community health facility, the greater the likelihood of women using a more permanent method rather than the injection (1.2).

The community-level random intercept term remained significant for both method-choice categories after the inclusion of the individual, household, community and health facility variables in the model. Thus, the variables included in the model did not account for a substantial amount of the variation in contraceptive method choice between communities.

\section{DISCUSSION}

These results highlight several community factors that are associated with contraceptive method choice in this South African setting. Women living in communities that were wealthier and had higher levels of female autonomy (as indicated by control over earnings) were more likely to be using either the pill or a more permanent method of contraception rather than the injection. Similarly, women in communities in which females had higher levels of education and higher mean ages at first sexual intercourse (again, indicative of higher levels of female autonomy) had a greater likelihood of using the pill instead of the injection. This suggests a profile of communities in which the use of injectable contraceptives dominates: communities that are characterized by poorer socioeconomic conditions and low female autonomy and that are lacking in social and economic opportunities for women.

Previous studies have highlighted wide racial disparities in contraceptive use in South Africa. Although black Africans account for $77 \%$ of the population, $61 \%$ live in poverty, and their contraceptive prevalence rate of $58 \%$ is lower than that of other groups (80\% for whites, $76 \%$ for Indians and Asians, and 69\% for coloreds). ${ }^{4}$ Choice of contraceptive method follows racial stratification: Whites, who rely less on public family planning services, utilize a 
wider range of modern contraceptive methods, whereas the black and colored populations rely heavily on the injection, which accounts for $35 \%$ and $27 \%$, respectively, of their method use. ${ }^{1,4}$ The disparities in method choice across racial groups may result from inequitable access to knowledge and services, or from individual preferences that predominate in some population groups. Because our sample comprised mostly blacks, the results may reflect the concentration of injectable use in poorer black communities in the Eastern Cape; variations in contraceptive choice seem to be present only in communities with greater socioeconomic development.

The high use of the injection in poorer black communities may also reflect the targeting of family planning efforts toward areas with the greatest demand. The potential for bias produced by the nonrandom placement of health services has been highlighted in studies examining the impact of public health interventions on individual health outcomes. ${ }^{54-56}$ Gertler and Molyneaux noted that the use of panel data can control for the endogeneity of program inputs by measuring the multivariate correlations between changes in the health outcomes and the explanatory variables, ${ }^{55}$ however, as is the case with the 1998 South Africa DHS, most commonly available data sources for the study of the determinants of contraceptive use in less developed nations are cross-sectional.

Health facility characteristics that were associated with contraceptive method choice indicate a relationship between quality of facilities and choice. Having more doctors present at health facilities was associated with increased use of both the pill and more permanent methods of contraception, suggesting that facilities with higher staffing levels may be better equipped to offer counseling on and provide a greater range of contraceptive methods. Women living in communities in which the health facility scored high on the facility asset index were more likely to be using the IUD or relying on male or female sterilization than to be using the injection, suggesting a relationship between facility preparedness and the ability to offer a range of methods. In contrast, the presence of more community health workers was associated with a lower likelihood of pill use than of injection use. Both of these methods are easily provided in a home setting by community health workers, who may have a preference for providing injectable contraceptives.

The community and health facility variables included in the analysis do not fully explain community-level variation in women's decisions to adopt a contraceptive method other than the injection. Unexplained variation in method choice between communities may reflect either the absence of variables that are not commonly collected in community surveys or less tangible factors that are difficult to quantify in surveys. The latter may include the presence of social networks within communities that act as vehicles for the transmission of contraceptive knowledge. Such networks may facilitate the sharing of positive experiences by early adopters, through which specific methods may become popular. ${ }^{29}$ The residual variation in contraceptive method choice observed here may be reflecting the absence of social network data in the DHS, or the lack of data that capture structural elements of the community environment. Community-level factors such as the presence of employment opportunities or institutions that facilitate social interactions may influence contraceptive method choice by providing access to economic and social resources. Additionally, beliefs about particular contraceptive methods that prevail within a community may be a strong influence on a woman's choice of methods, yet such forces are hard to measure in a large social survey and are absent from the current data.

\section{Limitations}

This study has several limitations. First, there is a dearth of data collected directly at the community level on variables related to contraceptive behavior, resulting in the reliance on community indicators derived from individual responses. While these indicators have been shown to be acceptable proxies for community data, ${ }^{53}$ the continued presence of community-level variation in contraceptive method choice demonstrates the need to collect data that directly measure some of the possible community influences on contraceptive behavior. Second, the health facility data were collected for government health facilities only. The private sector currently serves approximately $15 \%$ of family planning users in South Africa, with higher levels of privatesector utilization among the white and Asian populations. ${ }^{4}$ Gready et al. found that many South African women report negative experiences with government-operated family planning services, and have greater confidence in services offered by the private sector. ${ }^{57}$ Thus, these data are not capturing the complete service environment in the community, and it may be possible to explain more of the variation in contraceptive use with data that are representative of all family planning service providers.

A third limitation is that the sample is not representative of the South African population: Eastern Cape is the poorest province, and its unique socioeconomic setting has likely created a unique set of community influences on contraceptive method choice. Furthermore, our analysis included data only from health facilities that could be linked to enumeration districts, and omitted facilities were in areas not sampled by the DHS. Although it is possible that there are differences between linked and unlinked health facilities, the DHS is a nationally representative sample of individuals, and there is no evidence to suggest that the enumeration districts sampled in the Eastern Cape are in any way nonrepresentative of the whole province.

\section{Conclusions}

This study improves our understanding of the numerous ways in which contraceptive method choice is influenced by community characteristics, and provides new information on the synergistic effects of the community and health facility environments on contraceptive choice. However, 
significant community variation in method choice remains, highlighting the need for increased efforts to collect community-level data on the structural, behavioral and cultural dimensions of community environments. From a methodological perspective, future research needs to emphasize the collection of community-level data that can reduce unexplained variations in contraceptive behavior, and adopt a longitudinal approach to allow the disentangling of the effect of programs targeting contraceptive method choice.

From a program perspective, community-level, family planning-focused interventions should be aimed at the structural elements of communities that currently shape contraceptive behavior. In particular, certain community and health facility characteristics are clearly associated with the decision to adopt a method other than the injection. Our results should focus attention on expanding contraceptive method uptake and availability among poorer, predominantly black African communities in the Eastern Cape, as well as encourage the uptake of a wider variety of contraceptive methods in these communities.

\section{REFERENCES}

1. South Africa Department of Health, South African Medical Research Council and MEASURE DHS+, South Africa Demographic and Health Survey, 1998: Full Report, Pretoria, South Africa: Department of Health, 2002.

2. U.S. Bureau of the Census, International data base country summary: South Africa, <http://www.census.gov/ipc/www/idb/ country/sfportal.html>, accessed Mar. 24, 2008.

3. Burgard S, Factors associated with contraceptive use in late- and post-apartheid South Africa, Studies in Family Planning, 2004, 35(2): 91-104.

4. Swartz L, Expert group meeting on completing the fertility transition, paper presented at the Conference on Fertility and the Current South African Issues of Poverty, HIV/AIDS and Youth, Pretoria, South Africa, Oct. 24, 2002

5. Joint United Nations Programme on HIV/AIDS, South Africa: country situation analysis, <http://www.unaids.org/en/Country Responses/Countries/south_africa.asp>, accessed Feb. 11, 2008.

6. Maharaj P and Cleland J, Women on top: the relative influence of wives and husbands on contraceptive use in KwaZulu-Natal, Journal of Women and Health, 2005, 4l(2):31-41.

7. Myer L et al., Dual method use in South Africa, International Family Planning Perspectives, 2002, 28(2):119-121.

8. Stephenson RB et al., Contextual influences on modern contraceptive use in Sub-Saharan Africa, American Journal of Public Health, 2007, 97(7):1233-1240

9. Stephenson RB and Tsui AO, Contextual influences on reproductive health service use in Uttar Pradesh, India, Studies in Family Planning, 2002, 33(4):309-320

10. Bruce J, Fundamental elements of the quality of care: a simple framework, Studies in Family Planning, 1990, 21(2):61-91.

11. Mark KE et al., Contraception among HIV concordant and discordant couples in Zambia: a randomized controlled trial, Journal of Women's Health, 2007, 16(8):1200-1210.

12. Lindsay MK et al., The impact of knowledge of human immuno-de-ficiency virus serostatus on contraceptive choice and repeat pregnancy, Obstetrics \& Gynecology, 1995, 85(5 Pt. 1):675-679.

13. King R et al., A family planning intervention to reduce vertical transmission of HIV in Rwanda, AIDS, 1995, 9(Suppl. 1):45-51.
14. Baylies C, The impact of HIV on family size preference in Zimbabwe, Reproductive Health Matters, 2000, 8(15):77-86.

15. Link BG and Phelan J, Social conditions as fundamental causes of disease, Journal of Health and Social Behavior, 1995, 35(Suppl.):80-94.

16. Halloran ME and Struchiner CJ, Study designs for dependent happenings, Epidemiology, 1991, 2(5):331-338.

17. Koopman JS and Longini IM, Jr., The ecological effects of individual exposures and nonlinear disease dynamics in populations, American Journal of Public Health, 1994, 84(5):836-842.

18. Grady WR, Klepinger DH and Billy JOG, The influence of community characteristics on the practice of effective contraception, Family Planning Perspectives, 1993, 25(1):4-11.

19. Chacko $E$, Women's use of contraception in rural India: a villagelevel study, Health and Place, 2001, 7(3):197-208.

20. Magadi MA, Madise NJ and Rodrigues RN, Frequency and timing of antenatal care in Kenya: explaining the variations between women of different communities, Social Science \& Medicine, 2000, 51(4):551- 561.

21. Pebley AR, Goldman N and Rodriguez G, Prenatal and delivery care and childhood immunization: do family and community matter? Demography, 1996, 33(2):213-247.

22. Von Korff M et al., Multilevel research in epidemiologic research on health behaviors and outcomes, American Journal of Epidemiology, 1992, 135(10):1077-1082.

23. Diez-Roux AV, Investigating neighborhood and area effects on health, American Journal of Public Health, 2001, 91(11):1783-1789.

24. Stokols D, Establishing and maintaining healthy environments: toward a social ecology of health promotion, American Psychologist, 1992, 47(1):6-22

25. Duncan C, Jones K and Moon G, Context, composition and heterogeneity: using multilevel models in health research, Social Science E Medicine, 1998, 46(1):97-117.

26. Goldstein H, Multilevel Statistical Methods, London: Arnold, 2003

27. DiPrete TA and Forristal JD, Multilevel models: methods and substance, Annual Review of Sociology, 1994, 20:331-357.

28. Stephenson RB and Tsui AO, Contextual influences on reproductive wellness in northern India, American Journal of Public Health, 2003, 93(11):1820-1829.

29. Entwisle B et al., Community and contraceptive choice in rura Thailand: a case study of Nang Rong, Demography, 1996, 33(1):1-11.

30. Tuoane M, Diamond I and Madise N, Use of family planning services in Lesotho: the importance of quality of care and access, African Population Studies, 2003, 18(2):105-132.

31. Bongaarts J and Bruce J, The causes of unmet need for contraception and the social content of services, Studies in Family Planning, 1995, 26(2):57-75.

32. Tsui AO and Ochoa LH, Service proximity as a determinant of contraceptive behaviour: evidence from cross-national studies of survey data, in: Phillips JF and Ross JA, eds., Family Planning Programmes and Fertility, Oxford, UK: Clarendon Press, 1992.

33. Oliver R, Contraceptive use in Ghana: the role of service availability, quality and price, Living Standards Measurement Study Working Papers, Washington, DC: World Bank, 1995, No. 111

34. Hamid S and Stephenson RB, Provider and health facility influences on contraceptive adoption in urban Pakistan, International Family Planning Perspectives, 2006, 32(2):71-78.

35. Katende C, Gupta N and Bessinger R, Facility-level reproductive health interventions and contraceptive use in Uganda, International Family Planning Perspectives, 2003, 29(3):130-137.

36. RamaRao $S$ et al., The link between quality of care and contraceptive use, International Family Planning Perspectives, 2003, 29(2):76-83.

37. Seiber E and Bertrand J, Access as a factor in differential contraceptive use between Mayans and Ladinos in Guatemala, Health Policy and Planning, 2002, 17(2):167-177. 
38. Magnani RJ et al., The impact of the family planning supply environment on contraceptive intentions and use in Morocco, Studies in Family Planning, 1999, 30(2):120-132.

39. Steele F, Curtis SL and Choe M, The impact of family planning service provision on contraceptive use dynamics in Morocco, Studies in Family Planning, 1999, 30(1):28-42.

40. Blanc AK, Curtis SL and Croft TN, Monitoring contraceptive continuation: links to fertility outcomes and quality of care, Studies in Family Planning, 2002, 33(2):127-140.

41. DeGraff D, Bilsborrow RE and Guilkey DK, Community-level determinants of contraceptive use in the Philippines: a structural analysis, Demography, 1997, 34(3):385-398.

42. National Research Council, Factors Affecting Contraceptive Use in Sub-Saharan Africa, Washington, DC: National Academy Press, 1993.

43. Nazzar A et al., Developing a culturally appropriate family planning program for the Navrongo experiment, Studies in Family Planning, 1995, 26(6):307-324.

44. Diez-Roux AV, Bringing context back into epidemiology: variables and fallacies in multilevel analysis, American Journal of Public Health, 1998, 88(2):216-222.

45. Saha T, The Effect of Settlement Zones and Economic Diversity on Reproductive Behaviour in West Africa: West Africa Spatial Analysis Prototype Exploratory Analysis, Calverton, MD, USA: Macro International, 1998.

46. Entwisle B, Casterline JB and Sayed AA, Villages as contexts for contraceptive behavior in rural Egypt, American Sociological Review, 1989, 54(6):1019-1034

47. Entwisle B and Mason WM, Multilevel effects of socioeconomic development and family planning programs on children ever born, American Journal of Sociology, 1985, 91(3):616-649.

48. Nsemuklia GB et al., A Study of Factors Associated with Maternal Mortality in 1998, Lusaka, Zambia: Ministry of Health, United Nations Population Fund, Central Board of Health and University of Zambia, 1999.

49. Mahlalela X et al., Primary Health Care in the Eastern Cape Province 1997-2000, Bisho, South Africa: EQUITY Project, Department of Health and Management Sciences for Health, 2001.

50. Van Rensberg D et al., Primary health care facilities survey, in: Ntuli A, ed., South African Health Review 2000, Durban, South Africa: Health Systems Trust, 2001.

51. MEASURE Evaluation and EQUITY Project, 1998 South African Demographic and Health Survey Report for Eastern Cape Province, Bisho, South Africa: EQUITY Project, Department of Health and Management Sciences for Health, 2004.

52. MLwiN, computer program, Centre for Multilevel Modelling, $<$ http://www.cmm.bristol.ac.uk/MLwiN/index.shtml>, accessed May 24, 2007.

53. Blakely TA and Woodward AJ, Ecological effects in multi-level studies, Journal of Epidemiology \& Community Health, 2000, 54(5):367374.

54. Angeles G, Guilkey DK and Mroz TA, Purposive program placement and the estimation of family planning program effects in Tanzania, Journal of the American Statistical Association, 1998, 93(443): 884-899.

55. Gertler PJ and Molyneaux JW, How economic development and family planning programs combined to reduce Indonesian fertility, Demography, 1994, 31(1):33-63.

56. Pitt MM, Rosenzweig MR and Gibbons DM, The determinants and consequences of the placement of government programs in Indonesia, World Bank Economic Review, 1993, 7(3):319-348.

57. Gready M et al., South African women's experiences of contraception and contraceptive services, in: Ravindran S, Berer $\mathrm{M}$ and Cottingham J, eds., Beyond Acceptability: Users' Perspectives on Contraception, Geneva: Reproductive Health Matters for the World Health Organization, 1997.

\section{RESUMEN}

Contexto: Aunque un número creciente de estudios ha examinado la forma en que los factores comunitarios influyen en el uso de anticonceptivos, pocos han explorado cómo esos factores afectan la selección de métodos.

Métodos: Se utilizaron datos de la Encuesta de Demografía y Salud de Sudáfrica 1998, y de la Encuesta de Instituciones de Salud de Cabo Oriental del mismo año, para examinar la influencia de la comunidad y de las instituciones de salud en la selección de métodos en 1,165 mujeres de 15-49 años que vivían en Cabo Oriental. Las razones de riesgo relativo de modelos multinomiales multinivel evaluaron la forma en que la selección de métodos varió entre las comunidades.

Resultados: La probabilidad de usar la píldora o un método más permanente en vez de la inyección aumentó con la proporción de mujeres en una comunidad que controlaba sus ingresos (razones de riesgo relativo, 2.8-3.2). En contraste, en comunidades con mayores proporciones de mujeres con sólo educación primaria, las mujeres tuvieron menor probabilidad de usar píldoras en lugar de la inyección (0.1). Contar con un mayor número del personal médico estuvo asociado con una mayor probabilidad del uso de la píldora o un método más permanente (1.4-1.5), y el hecho de tener más métodos caducados en la clínica se asoció con un mayor uso de métodos permanentes (2.1). Varios otros factores relacionados con las instituciones de salud se asociaron con una menor probabilidad del uso de la píldora en vez de la inyección: mayores números de trabajadores de salud comunitarios y de enfermeras que hubieran recibido capacitación en VIH/SIDA en el último año (0.9 cada uno). Sin embargo, estas variables no explicaron una gran parte de la variación en la selección de métodos.

Conclusión: Futuras investigaciones deben poner énfasis en la recolección de datos sobre factores estructurales, culturales y de conductas a nivel de la comunidad, para ayudar a explicar la variación en la selección de métodos entre comunidades.

\section{RÉSUMÉ}

Contexte: De plus en plus d'études examinent l'influence des facteurs communautaires sur la pratique contraceptive. Peu considèrent cependant l'effet de ces facteurs sur le choix des méthodes.

Méthodes: Les données des enquêtes EDS sud-africaine et Eastern Cape Facility Survey de 1998 ont servi à examiner l'influence de la communauté et des établissements de santé sur les choix de méthode de 1.165 résidentes d'Eastern Cape âgées de 15 à 49 ans. Les rapports de risques relatifs de modèles d'analyse multinomiale multiniveaux ont permis d'évaluer la variation des choix d'une communauté à l'autre.

Résultats: La probabilité de choisir la pilule ou une méthode plus permanente, par rapport à l'injection, augmente avec la proportion de femmes, au sein d'une communauté, qui contrôlent leur revenu (rapport de risques, 2,8-3,2). En revanche, dans les communautés présentant de plus hautes proportions de femmes scolarisées au niveau primaire seule- 
ment, le choix de la pilule est moins probable que celui de l'injection $(0,1)$. Les dotations supérieures en médecins sont associées à une plus haute probabilité d'usage de la pilule ou d'une méthode plus permanente $(1,4-1,5)$ et les quantités supérieures de stocks de méthodes périmées, à une pratique accrue d'une méthode plus permanente $(2,1)$. Plusieurs facteurs d'établissement sont associés à une moindre probabilité d'usage de la pilule plutôt que de l'injection: nombres supérieurs d'agents sanitaires de communauté et, aux établissements, de personnel infirmier ayant reçu une formation sur le VIH/sida durant les 12 derniers mois écoulés (0,9 chacun). Ces variables ne justifient cependant pas, dans une mesure considérable, la variation dans le choix des méthodes.
Conclusion: La recherche à venir devra mettre l'accent sur la collecte de données de niveau communautaire relatives aux facteurs structurels, comportementaux et culturels pour expliquer la variation, dans le choix des méthodes, d'une communauté à l'autre.

\section{Acknowledgments}

This analysis was supported by the U.S. Agency for International Development (USAID) under cooperative agreement GPO-A-0003-00003-00 with the MEASURE Evaluation project. The conclusions and views expressed here are those of the authors and not necessarily those of USAID.

Author contact:rbsteph@sph.emory.edu

\section{NOTE TO AUTHORS AND REVIEWERS}

\section{New Procedure for Submitting a Manuscript}

International Family Planning Perspectives now has an online submission process through Manuscript Central. This new system will streamline our procedures for handling the growing number of manuscripts that we receive and will enable authors to track the progress of their submissions. To submit a manuscript, go to <http://mc.manuscriptcentral.com/ifpp $>$, and follow the instructions for uploading your paper and cover letter.

The Manuscript Central system will also be our main means of communicating with reviewers. Anyone who agrees to review a manuscript will be directed to the site for instructions on how to submit their review. 